\title{
CARBOIDRATOS E MATÉRIA SECA DE TUBÉRCULOS DE CULTIVARES DE BATATA INFLUENCIADOS POR DOSES DE NITROGÊNIO
}

\author{
Carbohydrates and dry matter in tubers of potato cultivars as affected by nitrogen doses
}

\author{
Heder Braun', Paulo Cezar Rezende Fontes ${ }^{2}$, Fernando Luiz Finger², Camilo Busato ${ }^{3}$, Paulo Roberto Cecon ${ }^{4}$
}

\begin{abstract}
RESUMO
Neste trabalho, objetivou-se avaliar o efeito de doses de nitrogênio $(\mathrm{N})$ sobre os teores de carboidratos (açúcares solúveis totais, açúcares redutores e amido), matéria seca e sólidos solúveis totais nos tubérculos de quatro cultivares de batata. Os tubérculos originaram-se de quatro experimentos, realizados simultaneamente no campo, no outono/inverno, na Universidade Federal de Viçosa. Em todos os experimentos, foi utilizado delineamento em blocos casualizados, com quatro repetições. Os tratamentos foram compostos de cinco doses de $\mathrm{N}\left(0,50,100,200\right.$ e $\left.300 \mathrm{~kg} \mathrm{ha}^{-1}\right)$ na forma de sulfato de amônio, aplicadas no plantio das cultivares Ágata, Asterix, Atlantic e Monalisa. Foram analisados os teores de matéria seca, açúcares solúveis totais, açúcares redutores, amido e sólidos solúveis totais nos tubérculos, após 30 dias de armazenamento a $5^{\circ} \mathrm{C}$ a $80-85 \%$ de umidade relativa. Em todas as cultivares, as doses de $\mathrm{N}$ apresentaram efeito quadrático sobre o teor de sólidos solúveis totais e não houve efeito sobre os teores de matéria seca e de amido nos tubérculos de batata. Dependendo da cultivar, as doses de $\mathrm{N}$ influenciam positivamente, ou não influenciam os teores de açúcares redutores e açúcares solúveis totais nos tubérculos de batata.
\end{abstract}

Termos para indexação: Solanum tuberosum L., adubação nitrogenada, qualidade de tubérculos, açúcares, amido, matéria seca.

\section{ABSTRACT}

This study aimed to evaluate the effect of nitrogen $(\mathrm{N})$ doses on carbohydrate (total soluble sugars, reducing sugars and starch), dry matter and total soluble solids contents in tuber of four potato cultivars. The tubers originated from four experiments, simultaneously conducted in the field, during fall/winter, at the Federal University of Viçosa. These experiments were set in randomized complete block and four repetitions and we evaluated the effects of five $\mathrm{N}$ rates $\left(0,50,100,200\right.$, and $\left.300 \mathrm{~kg} \mathrm{ha}^{-1}\right)$ on Agata, Asterix, Atlantic and Monalisa cultivars. Dry matter, total soluble sugars, reducing sugars, starch, and total soluble solids contents of the tubers were analyzed after a 30 -day storage at $5^{\circ} \mathrm{C} . \mathrm{N}$ rates presented quadratic effects on the total soluble solids and presented no effects on dry matter and starch contents for all cultivars. Depending on the cultivar, $\mathrm{N}$ rates had positive effects or did not affect reducing sugars and total soluble sugars contents in the tubers.

Index terms: Solanum tuberosum L., fertilization, tuber quality, sugars, starch, dry matter.

(Recebido em 16 de julho de 2008 e aprovado em 22 de maio de 2009)

\section{INTRODUÇÃO}

A batata (Solanum tuberosum L.) tem importância econômica entre as olerícolas e no mundo é o quarto cultivo alimentar mais importante depois do trigo, arroz e milho (Fontes \& Pereira, 2005). Em 2008, a produção brasileira de batata foi de 3.636.419 toneladas, com área plantada de 144.400 hectares, atingindo produtividade de $25,18 \mathrm{t} \mathrm{ha}^{-1}$. A produtividade mundial em 2007 foi de 16,65 $\mathrm{tha}^{-1}$ (Agrianual, 2009). O mercado brasileiro é abastecido por cultivares originárias da Holanda, Alemanha e Canadá, como Ágata' Asterix, Atlantic, Monalisa, entre dezenas de outras.

A batata é relevante alimento utilizado na dieta dos povos da maioria dos países. O tubérculo contém balanceada quantidade de proteínas, aminoácidos essenciais, carboidratos, fibras e potássio que torna o produto apropriado para a alimentação humana (Associação da Batata Brasileira-ABBA, 2008). Carboidratos são compostos orgânicos encontrados nos órgãos das plantas dentre as quais os tubérculos da batata. O amido corresponde por 60 a $80 \%$ da matéria seca e os açúcares, glicose, frutose e sacarose são os principais carboidratos presentes nos tubérculos. Ao atingir a maturação fisiológica, os tubérculos apresentam grânulos de amido e quantidades variáveis desses açúcares, dependendo das condições ambientais e de cultivo, cultivar e da interação entre os mesmos (Santerre et al., 1986). O amido e os açúcares são interconversíveis e a relação entre ambos depende de enzimas envolvidas na síntese e na

\footnotetext{
1Universidade Federal de Viçosa/UFV - 36570-000 - Viçosa, MG - hederbraun@hotmail.com

2Universidade Federal de Viçosa/UFV - Departamento de Fitotecnia - Viçosa, MG

${ }^{3}$ Instituto de Defesa Agropecuária e Florestal do Espírito Santo/IDAF - Colatina, ES

${ }^{4}$ Universidade Federal de Viçosa/UFV - Departamento de Informática - Viçosa, MG
} 
quebra do amido. O teor de açúcares é importante característica dos tubérculos destinados à fabricação de batata frita, na forma de chips e palitos, sendo determinado pelo genótipo e diversos fatores ambientais, durante o crescimento e desenvolvimento da cultura, como temperatura, programa de adubação e condições de armazenamento após a colheita (Kumar et al., 2004).

Após a colheita, os tubérculos são imediatamente consumidos ou armazenados, normalmente, em ambiente refrigerado. $\mathrm{O}$ armazenamento dos tubérculos a baixa temperatura $\left(4^{\circ} \mathrm{C}\right)$ é realizado para inibir a brotação, reduzir a infecção por microrganismos, diminuir a perda de massa fresca e permitir o aproveitamento industrial dos tubérculos por longo período após a colheita. Durante o armazenamento refrigerado, a superfície dos tubérculos tem maior pressão de vapor do que o ar, esultando em perda de água. Entretanto, a exposição à baixa temperatura induz à quebra do amido e acúmulo de sacarose, glicose $\mathrm{e}$ frutose nos tubérculos fenômeno conhecido como adoçamento. Aumento nos teores de carboidratos solúveis totais e de açúcares redutores em tubérculos de genótipos de batata, após o armazenamento a $4{ }^{\circ} \mathrm{C}$, foram verificados por Bacarin et al. (2005). A integração das informações existentes apontam para a inibição de ATPases e disfunção do fluxo de elétrons na célula, em razão do estresse pelo frio (Gounaris, 2001), havendo conexão entre a mobilização de açúcares e a necessidade da célula estressada utilizar mecanismos fermentativos para produzir energia. Em baixa temperatura ocorre acúmulo de adenosina tri-fosfato (ATP) no tubérculo, ativação da via alternativa e, simultaneamente, aumento nas concentrações de sacarose, substrato da invertase ácida no vacúolo que originará o acúmulo de açúcares redutores nos tubérculos (Duplessis et al., 1996).

O acúmulo de açúcares redutores nos tubérculos armazenados sob refrigeração é um dos fatores limitantes na produção de batata frita de alta qualidade (Sowokinos, 2001). Isso decorrente da formação de produtos de coloração escura, resultado da reação entre o grupamento carbonila do açúcar redutor (glicose e frutose) e o grupo amino dos aminoácidos, conhecida como reação de Maillard (Richardson et al., 1990). Dependendo do tempo de armazenamento, cultivar e grau de maturação dos tubérculos, os teores de amido e açúcares variam pela ocorrência de hidrólises químicas e/ou enzimáticas, reduzindo as quantidades de amido e aumentando as de açúcares.

Além do teor de açúcares redutores, o teor de matéria seca é importante parâmetro de qualidade para estimar o potencial dos tubérculos de batata de produzir produtos processados com apropriados atributos de qualidade. Cacace et al. (1994) relataram que as cultivares de batata podem ser agrupadas em alto teor MS (superior a 20\%); teor intermediário (18 a 19,9\%) e baixo teor de MS (inferior a 17,9\%). O teor de açúcar depende, em parte, do teor de matéria seca do tubérculo que é uma característica intrínseca do cultivar (Cacace et al., 1994) modulada pelo manejo fitotécnico e por condições climáticas.

Informações sobre a influência de fertilizantes, especificamente do $\mathrm{N}$, sobre a qualidade de tubérculos de batata tem sido obtidas (Mitrus et al., 2003; Goffart et al., 2008), mas os resultados são variáveis, pois a interações entre dose de $\mathrm{N}$, genótipo e condições de crescimento da planta são complexas. Dependendo do ano, dose de $\mathrm{N}$ acima da recomendada aumentou o teor de açúcares nos tubérculos de batata (Long et al., 2004) e diminuiu o teor de amido dos tubérculos (Westermann et al., 1994). Por outro lado foi, verificado que incrementos, na dose de $\mathrm{N}$ aumentaram o teor de amido dos tubérculos (El-Galil, 2006). Parece que o N está relacionado com o acúmulo de açúcar e amido via efeito na produção de matéria seca e maturação do tubérculo, fatores influenciados pela complexa interação dose de $\mathrm{N}$, genótipo, condições ambientais e práticas culturais adotadas. São escassas as pesquisas nas condições brasileiras, avaliando o efeito de doses de $\mathrm{N}$ sobre os teores de matéria seca e de carboidratos em tubérculos de cultivares de batata, após período de armazenamento dos tubérculos em condição refrigerada. Assim, conduziuse este trabalho, com o objetivo de determinar o efeito de doses de $\mathrm{N}$ sobre os teores de carboidratos, matéria seca e de sólidos solúveis totais nos tubérculos armazenados de quatro cultivares de batata.

\section{MATERIAL E MÉTODOS}

Os experimentos foram conduzidos na Horta de Pesquisas do Departamento de Fitotecnia (DFT) da Universidade Federal de Viçosa (UFV), na época de outono/ inverno (abril-julho de 2006), solo Podzólico VermelhoAmarelo Câmbico. Durante o experimento, os valores médios mensais de temperaturas máxima e mínima média do ar, de umidade relativa e precipitação pluvial foram de $24,9{ }^{\circ} \mathrm{C} ; 12,7{ }^{\circ} \mathrm{C} ; 90,2 \%$ e $20,7 \mathrm{~mm}$, respectivamente.

Foram instalados quatro experimentos, simultaneamente, no campo. Cada experimento correspondeu a uma cultivar de batata (Solanum tuberosum L.): Ágata, Asterix, Atlantic e Monalisa, respectivamente, as quais estão descritas em (ABBA, 2009). Os tratamentos consistiram-se de cinco doses de $\mathrm{N}(0,50,100,200$ e $300 \mathrm{~kg}$ $\left.\mathrm{ha}^{-1} \mathrm{de} \mathrm{N}\right)$, aplicadas no sulco, em pré-plantio, utilizando- 
se o sulfato de amônio. Os experimentos foram instalados no delineamento em blocos casualizados, com quatro repetições. Cada parcela de 3,0 x 1,75 m foi constituída de 28 plantas em quatro linhas, espaçadas de $0,75 \mathrm{~m}$ entre si e $0,25 \mathrm{~m}$ entre plantas. As duas linhas laterais e as duas plantas das extremidades das linhas centrais serviram como bordadura, totalizando 10 plantas úteis.

Antecipadamente, a área foi submetida a dois plantios sucessivos de milho, sem utilização de adubo nitrogenado, com o objetivo de reduzir o $\mathrm{N}$ disponível no solo. As plantas de milho foram cortadas mecanicamente $\mathrm{e}$ retiradas da área. Após a retirada do milho, foi efetuada a amostragem do solo para determinar a necessidade de calagem e caracterização química e física.. Em seguida, realizou-se aração profunda do solo, com arado de aiveca e duas passagens de grade niveladora, com posterior sulcamento. Antes da instalação dos experimentos, características químicas e granulométricas foram determinadas pela análise de amostras das camadas de 0$20 \mathrm{~cm}$ de profundidade. O solo apresentava classificação textural argilosa, com 28, 25 e $47 \mathrm{dag}_{\mathrm{kg}^{-1}}$ de areia, silte e argila, respectivamente, e as seguintes características químicas: $\mathrm{pH}$ em água $=4,60 ; \mathrm{N}^{-\mathrm{NO}_{3}}=6.28 \mathrm{mg} \mathrm{kg}^{-1}$; Matéria orgânica $=27,4$ dag $\mathrm{kg}^{-1} ; \mathrm{P}=66 \mathrm{mg} \mathrm{dm}^{-3} ; \mathrm{K}=178 \mathrm{mg} \mathrm{dm}^{-3}$; $\mathrm{Ca}^{2+}=4,43 \mathrm{cmolc} \mathrm{dm}^{-3} ; \mathrm{Mg}^{2+}=0,80 \mathrm{cmolc} \mathrm{dm}^{-3} ;$ Acidez trocável $\left(\mathrm{Al}^{3+}\right)=0,00 \mathrm{cmolc} \mathrm{dm}^{-3}$; Acidez potencial $(\mathrm{H}+\mathrm{Al})$ $=3,47 \mathrm{cmolc} \mathrm{dm}^{-3}$; Soma de bases $(\mathrm{SB})=5,68 \mathrm{cmolc} \mathrm{dm}^{-3}$; CTC efetiva (t) = 5,68 cmolc dm $\mathrm{dm}^{-3}$ CTC a pH 7,0 (T) = 9,15 cmolc dm ${ }^{-3}$ e Saturação de bases $(\mathrm{V})=62,50 \%$.

Três dias antes do plantio, os fertilizantes foram aplicados nos sulcos e misturados com o solo. As quantidades por hectare foram: $1.800 \mathrm{~kg}$ de superfosfato simples; $384 \mathrm{~kg}$ de cloreto de potássio; $200 \mathrm{~kg}$ de sulfato de magnésio; 10 kg de bórax; $10 \mathrm{~kg}$ de sulfato de zinco; 10 $\mathrm{kg}$ de sulfato de cobre e $0,5 \mathrm{~kg}$ de molibdato de sódio e o sulfato de amônio nas cinco doses de $\mathrm{N}$ estabelecidas. Além dos adubos, foi feita a aplicação do inseticida Carbofuran, no sulco.

O plantio dos tubérculos em condições ideais de brotação das quatro cultivares foi realizado em sulcos, no dia 03 de abril de 2006. Foram utilizadas batatas-semente certificadas, com massa média de $70 \mathrm{~g}$, previamente brotadas. A cultura foi conduzida, seguindo as orientações de Fontes \& Pereira (2005) e, durante o ciclo da cultura, foram feitas pulverizações com fungicidas e inseticidas de forma preventiva. Aos 22 dias após a emergência (DAE), com enxada, efetuou-se a amontoa. As irrigações foram efetuadas por aspersão convencional, com turno de rega de cinco dias, no período da manhã, seguindo-se o procedimento adotado por Nunes (2004), com suspensão de uma semana antes da colheita. A colheita dos tubérculos ocorreu quando a parte aérea das plantas estava completamente seca, aos 88, 92, 91 e 84 DAE para as cultivares Ágata, Asterix, Atlantic e Monalisa, respectivamente. Os tubérculos permaneceram sobre o solo por duas horas para o secamento da película, e posteriormente, foram levados para o galpão, onde foram classificados em tipo comercial e tipo não-comercial; os tubérculos foram classificados nas classes I, II e III, de acordo com o diâmetro transversal, seguindo-se a portaria 69, publicada no DOU de 23/02/1995, em que a classe I apresenta diâmetro e" $8,5 \mathrm{~cm}$; a classe II $>4,5<8,5 \mathrm{~cm}$; a classe III $>3,3<4,5 \mathrm{~cm}$; e a classe 4 : d" a $3,3 \mathrm{~cm}$. Os tubérculos com defeitos graves e os menores que $3,3 \mathrm{~cm}$ foram classificados como tipo não-comercial.

Após a classificação, foram retiradas amostras de tubérculos comerciais de cada parcela, pesadas e posteriormente colocadas em estufa a $70^{\circ} \mathrm{C}$, até atingirem massa constante, para a determinação do teor de matéria seca (MS). Posteriormente, os tubérculos comerciais foram levados para câmara fria, onde permaneceram armazenados a $5^{\circ} \mathrm{C}$, por 30 dias à $80-85 \%$ umidade relativa (UR). Nesses tubérculos, foram determinados os teores de açúcares solúveis totais (AST), amido, açúcares redutores (AR) e sólidos solúveis totais ( ${ }^{\circ}$ Brix).

A quantificação de AST nos tubérculos foi realizada segundo o método Fenol-sulfúrico (Dubois et al., 1956). O resíduo retido em filtro foi secado em estufa a $65^{\circ} \mathrm{C}$ e armazenado em dessecador para determinação de amido. Sempre em duplicata, foram feitas a diluição da amostra e o preparo das soluções padrões de sacarose $\left(0,25,50,75,100 \mu \mathrm{g} \mathrm{mL} \mathrm{m}^{-1}\right)$. Para cada réplica foram pipetados $0,5 \mathrm{~mL}$ da amostra que foi colocado em tubo de ensaio onde foram adicionados $0,5 \mathrm{~mL}$ de fenol a $5 \%$ e 2,5 $\mathrm{mL}$ de $\mathrm{H}_{2} \mathrm{SO}_{4}$ concentrado. Os tubos foram agitados em vortex e colocados em banho de gelo. Procedeu-se a leitura em espectrofotômetro no comprimento de onda de $\lambda=$ $490 \mathrm{~nm}$.

No resíduo proveniente da extração dos AST. foi determinado o teor de amido, pela metodologia descrita por McCready et al. (1950), sendo o resultado multiplicado pelo fator 0,9. Multiplica-se por 0,9, porque na formação do amido há a remoção de uma molécula de água.

A quantificação do teor de AR foi realizada no mesmo extrato alcoólico usado na quantificação dos AST, conforme método Somogy-Nelson (Nelson, 1944). Os valores foram comparados com a curva padrão de glicose.

Para a quantificação do teor de sólidos solúveis totais ( $\left.{ }^{\circ} \mathrm{Brix}\right)$, foram retiradas $10 \mathrm{~g}$ de massa fresca de três tubérculos. As amostras foram espremidas e gotas do suco 
celular foram colocadas em refratômetro realizando-se as leituras em ${ }^{\circ} \mathrm{Brix}$, as quais foram corrigidas para $25^{\circ} \mathrm{C}$.

Os valores ótimos dos teores de MS, AST, AR, amido e sólidos solúveis totais ( ${ }^{\circ}$ Brix) para cada cultivar foram estimados por metodologia usada para o cálculo do teor ótimo de nutriente na matéria seca de plantas (Fontes \& Ronchi, 2002), utilizando-se a dose de $\mathrm{N}$ que proporcionou a máxima produtividade de tubérculo comercial de cada cultivar (dados não mostrados).

Cada experimento foi analisado individualmente. Os dados foram submetidos às análises de variância e de regressão. Os modelos de regressão foram escolhidos, baseando-se: na ocorrência biológica, na significância dos coeficientes de regressão, adotando-se o teste t e o nível de até $5 \%$ de probabilidade e no coeficiente de determinação $\left(\mathrm{r}^{2} / \mathrm{R}^{2}\right)$.

\section{RESULTADOS E DISCUSSÃO}

Não houve efeito de doses de $\mathrm{N}$ sobre o teor de matéria seca (MS) nos tubérculos de todas as cultivares sendo que os valores médios foram de 16,54; 16,63; 21,45 e $16,78 \%$ para Ágata, Asterix, Atlantic e Monalisa, respectivamente (Tabela 1). Há relatos na literatura que o aumento na dose de $\mathrm{N}$ pode retardar a maturação dos tubérculos (O’beirne \& Cassidy, 1990) e, com isso, pode reduzir o teor de MS nos tubérculos (Oliveira et al., 2006). O teor de MS é um das mais importantes características determinantes da textura do tubérculo, após o cozimento (McComber et al., 1988) e relaciona-se diretamente com a densidade específica do tubérculo.

O teor de MS também é relevante para o processamento industrial, sendo critério preponderante para a indústria classificar os tubérculos de batata. $\mathrm{O}$ teor de MS > 20\% é compatível com o requerido pelas indústrias de processamento (Pereira et al., 2007). Tubérculos de batata que apresentam alto teor de MS melhoram o rendimento industrial, além de reduzir a absorção de gordura, durante o processo de fritura, resultando num produto processado de melhor qualidade, como o chips mais crocante (Lulai \& Orr, 1979). A cultivar 'Atlantic' pode ser considerada de boa qualidade para o processamento industrial, pois apresentou 21,45\% de MS, aquém de 23,0\% relatados para a cultivar em outras condições de cultivo (Pereira et al., 2007).

Em todas as cultivares, não houve efeito de doses de $\mathrm{N}$ sobre o teor de amido nos tubérculos que foi de 10,97; 13,32; 11,31 e 13,30 g/100 g de MF para Ágata, Asterix, Atlantic e Monalisa, respectivamente. Em tubérculos de 'Atlantic', oriundos de plantios realizados no outono e primavera, após 30 dias de armazenamento a $2{ }^{\circ} \mathrm{C}$, foram encontrados os teores de amido de 11,20 e 21,20 g/100 g de MF, respectivamente (Chapper et al., 2002). Valores menores, 5,4 e 11,6 g/100 g de MF, foram obtidos para 'Atlantic', aos 100 dias após o plantio, em tubérculos colhidos no outono e primavera, respectivamente (Pastorini et al., 2003).

Alta dose de $\mathrm{N}$ pode decrescer o teor de amido nos tubérculos de batata (Westermann et al., 1994; Shan et al., 2004), fato não observado nas quatro cultivares. Aumento na dose de $\mathrm{N}$ provocou decréscimo no nível de desintegração da batata assada (Hegney \& McPharlin, 2000; Hejlová \& Blahovec, 2007). Isso ocorre em razão da redução no teor de amido e na densidade do tubérculo (O’beirne \& Cassidy, 1990). Diversos fatores como cultivar, época do ano, temperatura e tempo de armazenamento podem influenciar o teor de amido nos tubérculos (Cacace et al., 1994; Nourian et al., 2003).

$\mathrm{O}$ efeito de doses de $\mathrm{N}$ sobre o teor de açúcares solúveis totais (AST) foi dependente de cultivar. Assim, não houve efeito de doses de N sobre o teor de AST para 'Atlantic' e 'Monalisa' (Tabela 1) e o oposto ocorreu para ‘Ágata' e 'Asterix' (Figura 1). O teor de AST está relacionado com a atividade das enzimas responsáveis pela degradação do amido e pela redução da atividade respiratória, o que resulta em acúmulo desses carboidratos. O teor ótimo de AST na massa fresca de tubérculos das quatro cultivares variou de 0,84 a 1,56 g/100 g de MF (Tabela 1). Valores médios de AST de 1,67 e 1,79 g/100g de MF em tubérculos das cultivares 'Atlantic' e Pérola, respectivamente, foram encontrados por Pastorini et al. (2003). Além da temperatura do ambiente de armazenamento, fatores como a degradação do amido, exportação de açúcares para os amiloplastos ou a biossíntese de sacarose podem influenciar o acúmulo de açúcares solúveis totais em tubérculos de batata (Zrenner et al., 1996).

$\mathrm{O}$ efeito de doses de $\mathrm{N}$ sobre o teor de açúcares redutores (AR) na polpa de tubérculos foi dependente de cultivar, não havendo efeito em Asterix e Atlantic. Por outro lado, houve efeito quadrático e linear positivo de dose de $\mathrm{N}$ sobre o teor de AR para 'Ágata' e 'Monalisa', respectivamente (Figura 2). É relatado decréscimo no teor de AR nos tubérculos com o aumento na fertilização nitrogenada (Kolbe et al., 1995). Por outro lado, Long et al. (2004) verificaram que o excesso de $\mathrm{N}$ aumentou o teor de AR e a sacarose nos tubérculos.

Os teores ótimos de AR na massa fresca de tubérculos foram 1,55; 0,90; 0,50 e 1,31 g/100g para 'Ágata', 'Asterix', 'Atlantic' e 'Monalisa', respectivamente. Em todas as cultivares, os teores de AR foram relativamente superiores ao encontrado por Nelson et al. (1998) que foi 
de $0,20 \mathrm{~g} / 100 \mathrm{~g}$ MF. Provavelmente, isso ocorreu em razão de terem sido os tuberculos armazenados por 30 dias a 5 ${ }^{\circ} \mathrm{C}$, ocorrendo, nesse período, a quebra do amido e acúmulo de AR. Nourian et al. (2003) relataram que a degradação do amido ocorre rapidamente com a diminuição da temperatura, enquanto a variação dos teores de açúcares totais e redutores está diretamente relacionada com o tempo de armazenamento dos tubérculos. Adicionalmente, a quantidade de açúcares acumulados em resposta ao frio varia com a cultivar.

Para todas as cultivares, houve efeito positivo e quadrático de dose de $\mathrm{N}$ sobre o teor de sólidos solúveis totais (SST) (Figura 3). O valor ótimo de SST foi 5,32; 5,12; 6,07 e 4,93 'Brix para 'Ágata', 'Asterix', 'Atlantic' e Monalisa, respectivamente. Elevação do ( ${ }^{\circ}$ Brix) pode ocorrer em razão da conversão do amido em açúcares, durante o armazenamento, no frio (Deiting et al., 1998). Em condições brasileiras, Robles (2003) encontrou valores de 5,47 ${ }^{\circ}$ Brix para 'Monalisa' e 5,94 ${ }^{\circ}$ Brix para 'Atlantic' nos tubérculos de batata. Cardoso et al. (2007) relatou que o uso do parcelamento e da dose da adubação nitrogenada e potássica não contribuíram para o aumento da sólidos solúveis totais nos tubérculos de batata. Esses autores relataram valor médio de $3,45^{\circ}$ Brix nos tubérculos da cultivar Vivaldi.

Tabela 1 - Teores de matéria seca, carboidratos (açúcares solúveis totais, açúcares redutores e amido) associados à dose de nitrogênio que proporcionou a máxima produtividade comercial de tubérculos ${ }^{1}$ das cultivares de batata Ágata, Asterix, Atlantic e Monalisa. Viçosa (2006).

\begin{tabular}{lcccc}
\hline & \multicolumn{4}{c}{ Cultivares } \\
\cline { 2 - 5 } Características químicas & 'Ágata' & 'Asterix’ & 'Atlantic' & 'Monalisa' \\
\hline Matéria seca - MS (\%) & $16,54^{\mathrm{ns}}$ & $16,63^{\mathrm{ns}}$ & $21,45^{\mathrm{ns}}$ & $16,78^{\mathrm{ns}}$ \\
Açúcares solúveis totais - AST (g/100g MF) & 1,56 & 1,00 & $0,84^{\mathrm{ns}}$ & $1,44^{\mathrm{ns}}$ \\
Açúcares solúveis totais - AST (g/100g MS) & 9,45 & 6,02 & $3,93^{\mathrm{ns}}$ & $8,58^{\mathrm{ns}}$ \\
Açúcares redutores - AR (g/100g MF) & 1,55 & $0,90^{\mathrm{ns}}$ & $0,50^{\mathrm{ns}}$ & 1,31 \\
Açúcares redutores - AR (g/100g MS) & 9,34 & $5,46^{\mathrm{ns}}$ & $2,34^{\mathrm{ns}}$ & 7,92 \\
Amido (g/100g MF) & $10,97^{\mathrm{ns}}$ & $13,32^{\mathrm{ns}}$ & $11,31^{\mathrm{ns}}$ & $13,30^{\mathrm{ns}}$ \\
Amido (g/100g MS) & $66,38^{\mathrm{ns}}$ & $80,14^{\mathrm{ns}}$ & $52,82^{\mathrm{ns}}$ & $79,36^{\mathrm{ns}}$ \\
Sólidos solúveis totais - SST ( ${ }^{\mathrm{o}}$ Brix) & 5,32 & 5,12 & 6,07 & 4,93 \\
\hline
\end{tabular}

'Para 'Ágata', 'Asterix', 'Atlantic' e 'Monalisa' foram 168,18; 212,22; 175,45 e 193,18 kg ha' ${ }^{-1}$ de N, respectivamente.

${ }^{2} \mathrm{MF}$ - Massa fresca

${ }^{3}$ MS - Massa seca

${ }^{\text {ns }}$ Denota não significância da dose de N sobre a característica analisada em cada cultivar.
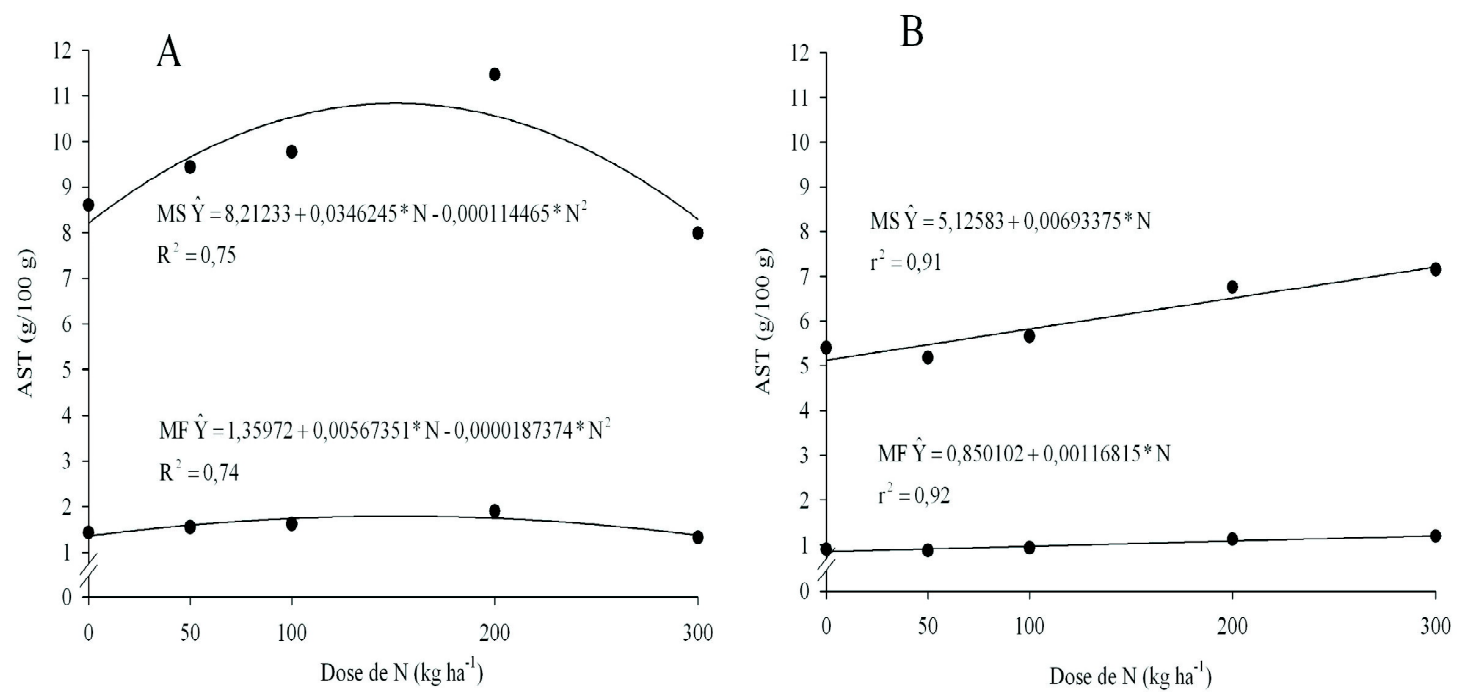

Figura 1 - Teor de açúcares solúveis totais (AST) nas massas fresca (MF) e seca (MS) de tubérculos das cultivares Ágata (A) e Asterix (B), em função de doses de nitrogênio (N). 

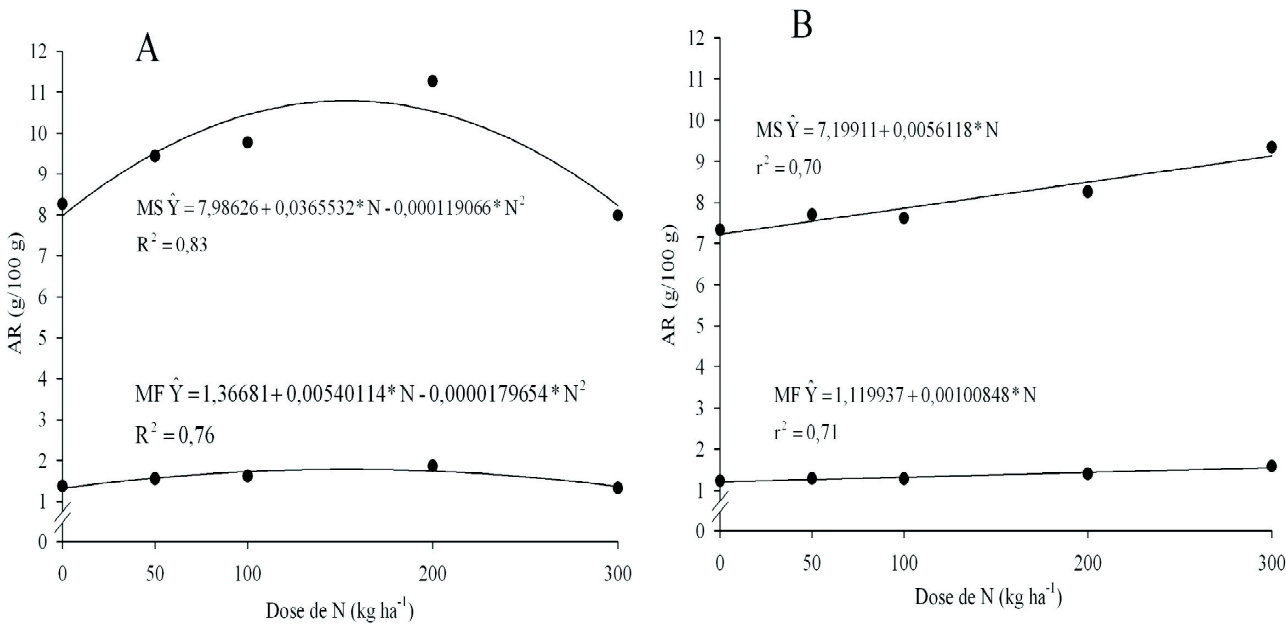

Figura 2 - Teor de açúcares redutores (AR) na massa fresca (MF) e seca (MS) de tubérculos da cultivar Ágata (A) e Monalisa (B), em função de doses de nitrogênio $(\mathrm{N})$.
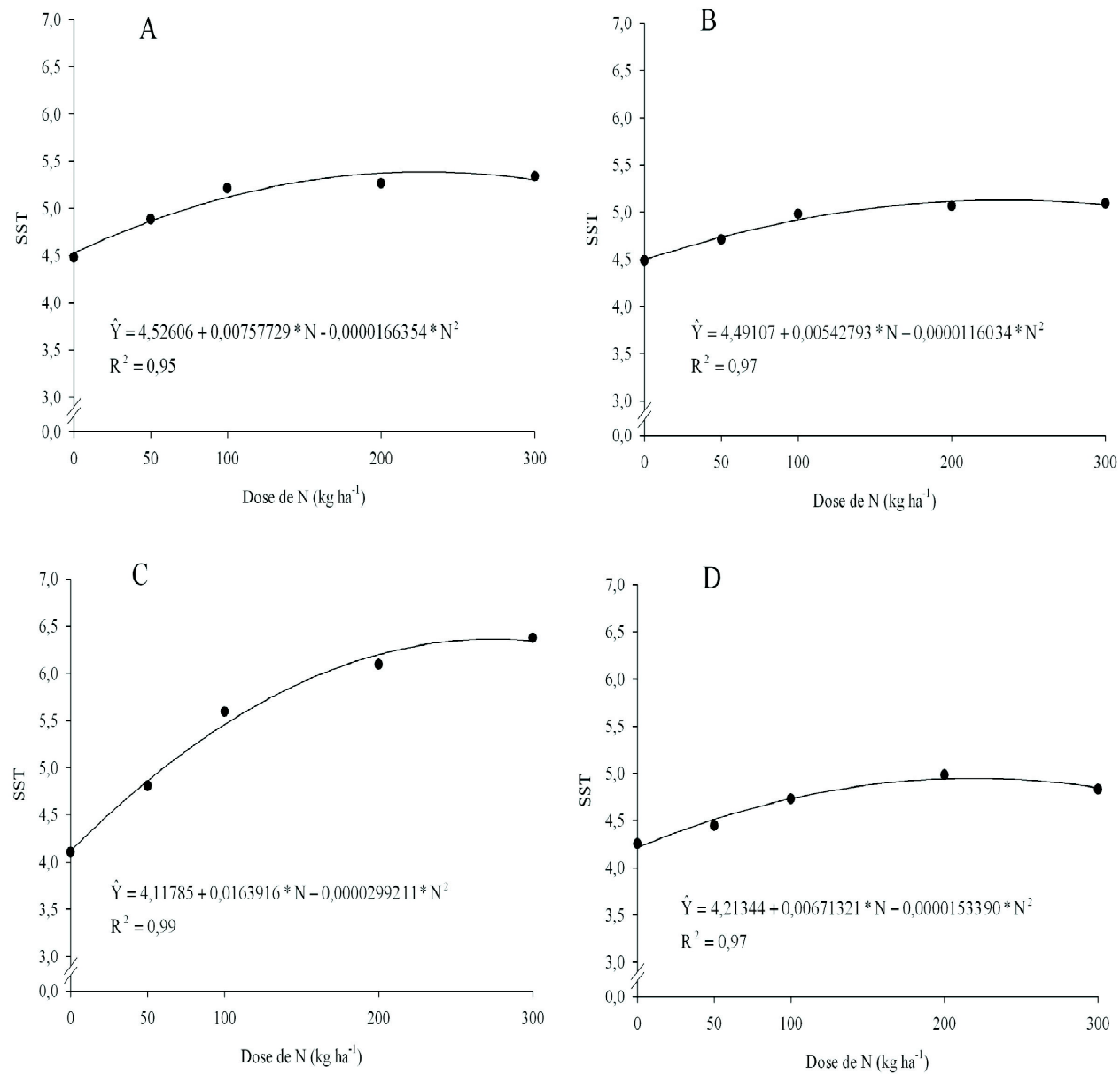

Figura 3 - Teor de sólidos solúveis totais (SST) nos tubérculos de batata, das cultivares Ágata (A), Asterix (B), Atlantic (C) e Monalisa (D), em função de doses de nitrogênio (N). 
Plantas adequadamente adubadas com N apresentam menor concentração de açúcar nos tubérculos do que aquelas com deficiência ou excesso de N, tanto no momento da colheita, quanto após armazenamento (Kumar et al., 2004). No presente estudo foi considerada adequada a dose de $\mathrm{N}$ que propiciou a máxima produção de tubérculos comerciais. Nessa condição, os níveis ótimos de MS, AST, AR, amido e sólidos solúveis totais estimados estão mostrados na Tabela 1 .

Para todas as cultivares, o nível ótimo dos teores de MS e de amido nos tubérculos não dependeu da dose de $\mathrm{N}$ e o inverso aconteceu com SST que dependeu da dose de N. O nível ótimo dos teores de AST e AR nos tubérculos de 'Ágata', AST em 'Asterix' e AR em 'Monalisa' dependeram da dose de $\mathrm{N}$.

\section{CONCLUSÕES}

Doses de N no plantio:

- tem efeito positivo e de forma quadrática sobre o teor de sólidos solúveis totais nos tubérculos das quatro cultivares;

- não tem efeito sobre os teores de matéria seca e de amido nos tubérculos das quatro cultivares;

- dependendo da cultivar, influenciam positivamente, ou não, nos teores de açúcares redutores e açúcares solúveis totais.

\section{AGRADECIMENTOS}

A CAPES, CNPq e FAPEMIG pela concessão de bolsas e de recursos para o projeto.

\section{REFERÊNCIAS BIBLIOGRÁFICAS}

\section{AGRIANUAL. Anuário estatístico da agricultura} brasileira. São Paulo: FNP, 2009.

\author{
ASSOCIAÇÃO DA BATATA BRASILEIRA. A batata \\ como alimento. Disponível em: <http:// \\ LWw.abbabatatabrasileira.com.br/2008/ \\ abatata.asp?id_BAT=3\$. Acesso em: 5 nov. 2008.
}

\section{ASSOCIAÇÃO DA BATATA BRASILEIRA. Batata \\ variedades. Disponível em: $<\mathrm{http}: / /$ \\ 'WwW.abbabatatabrasileira.com.bri \\ abatata_variedades.htm}

BACARIN, M.A.; FERREIRA, L.S.; DEUNER, S.; BERVALD, C.M.P.; ZANATTA, E.R.; LOPES, N.F. Carboidratos não estruturais em tubérculos de batata recondicionados após o armazenamento sob diferentes temperaturas. Horticultura Brasileira, Brasília, v.23, n.3, p.799-804, jul./set. 2005.
CACACE, J.E.; HUARTE, M.A.; MONTI, M.C.

Evaluation of potato cooking quality in Argentina. American Potato Journal, v.71, p.145-153, 1994.

CARDOSO, A. D.; ALVARENGA, M. A. R.; Melo T. L.; VIANA, A. E. S. Produtividade e qualidade de tubérculos de batata em função de doses e parcelamentos de nitrogênio e potássio. Ciência e Agrotecnologia, Lavras, v. 31, n. 6, p. 1729-1736, nov./dez., 2007.

CHAPPER, M.; BACARIN, M.A.; PEREIRA, A.S.; TERRIBLE, L.C. Carboidratos não estruturais em tubérculos de dois genótipos de batata armazenados em duas temperaturas. Horticultura Brasileira, Brasília, v.20, n.4, p.583-588, dez. 2002.

DEITING, U.; ZRENNER, R.; STITT, M. Similar temperature requirement for sugar accumulation and for the induction of new forms of sucrose phosphate synthase and amylase in cold-stored potato tubers. Plant, Cell and Environment, v.21, p.127-138,1998.

DUBOIS, M.; GILLER, K.A.; HAMILTON, J. K.; REBERS, P.A.; SMITH, F. Colorometric method for determinations of sugars and related substance. Analytic Chemistry, v.28, p.350-356, 1956.

DUPLESSIS, P.M.; MARANGONI, A.G.; YADA, R.Y. A mechanism for low temperature induced sugar accumulation in stored potato tubers: The potential role of the alternative pathway and invertase. American Potato Journal, v.73, p.483-494, 1996.

EL-GALIL, A.A. Fertilizer-N dynamics in the soil and yield response of potatoes as affected by methods of $\mathrm{N}$ application. Journal of Applied Sciences Research, v.2, n.9, p.613-623, 2006.

FONTES, P.C.R.; PEREIRA, P.R.G. Nutrição mineral de hortaliças. In: FONTES, P.C.R. (Ed.). Olericultura: teoria e prática. Viçosa, MG: UFV, 2005. p.39-55.

FONTES, P.C.R.; RONCHI, C.P. Critical values of nitrogen indices in tomato plants grown in soil and nutrient solution determined by different statistical procedures. Pesquisa Agropecuária Brasileira, Brasília, v.37, n.10, p.1421-1429, out. 2002.

GOFFART, J.P.; OLIVIER, M.; FRANKINET, M. Potato crop nitrogen status assessment to improve $\mathrm{N}$ fertilization management and efficiency: past-presentfuture. Potato Research, v.51, p.355-383, 2008. 
GOUNARIS, Y. A qualitative model for the mechanism of sugar accumulation in cold-stressed plant tissues. Theory in Biosciences, v.120, n.2, p.149-165, 2001.

HEGNEY, M.A.; MCPHARLIN, I.R. Response of summer planted potatoes to level of applied nitrogen and water. Journal of Plant Nutrition, v.23, p.197-218, 2000.

HEJLOVÁ, A.; BLAHOVEC, J. Role of cultivation conditions in potato sloughing as indicated by CPEM method. Plant, Soil and Environment, v.53, n.9, p.403412, 2007.

KOLBE, H.; MULLER, K.; OLTEANU, G.; GOREA, T. Effects of nitrogen, phosphorous and potassium fertilizer treatments on weight-loss and changes in chemical-composition of potato-tubers stored at $4^{\circ} \mathrm{C}$. Potato Research, v.38, p.97-107, 1995.

KUMAR, D.; SINGH, B.P.; KUMAR, P. An overview of the factors affecting sugar content of potatoes. Annals of Applied Biology, v.145, n.3, p.247-256, 2004.

LONG, C.M.; SNAPP, S.S.; DOUCHES, D.S.; CHASE, R.W. Tuber yield, storability and quality of Michigan cultivars in response to nitrogen management and seedpiece spancing. American Journal of Potato Research, v.81, p.347-357, 2004.

LULAI, E.C.; ORR, P.H. Influence of potato specific gravity on yield and oil content of chips. American Potato Journal, v.56, n.2, p.379-390, 1979.

McCOMBER, D.R.; OSMAN, E.M.; LOHNES, R.A. Factors related to potato mealiness. Journal of Food Science, v.53, p.1423-1426, 1988.

McCREADY, R.M.J.; GUGGOLZ, J.; SILVEIRA, V.V.; OWENS, H.H. Determination of starch and amylase in vegetable. Analytic Chemistry, v.22, p.1156-1158, 1950.

MITRUS, J.; STANKIEWICZ, C.; STEÆ, E.; KAMECKI, M.; STARCZEWSKI, J. The influence of selected cultivation on the content of total protein and amino acids in the potato tubers. Plant Soil Environment, v.49, n.3, p.131-134, 2003.

NELSON, D.G.; JENKINS, P.D.; GILLISON, T.C. Processing potencial of potato cultivars at early harvests. Potato Research, v.31, n. 4, p.633-642, 1998.
NELSON, N.A. A photometric adaptation of Somagy method for determination of glucose. Journal Biology Chemistry, v.135, p.136-137, 1944.

NOURIAN, F.; RAMASWAMY, H.S.; KUSHALAPPA, A.C. Kinetics of quality change associated with potatoes stored at different temperatures.

Lebensmittel-Wissenschaft und-Technologie, Berlin, v.36, p.49-65, 2003.

NUNES, J.C.S. Sistema de preparo do solo para o plantio manual e mecanizado da batateira irrigada por aspersão e gotejamento. 2004. 120f. Tese (Doutorado em Fitotecnia)-Universidade Federal de Viçosa, Viçosa, 2004.

O'BEIRNE, D.; CASSIDY, J.C. Effects of nitrogen fertiliser on yield, dry matter content and flouriness of potatoes. Journal of the Science of Food Agriculture, v.52, p.351-363, 1990.

OLIVEIRA, V.R.; ANDRIOLO, J.L.; BISOGNIN, D.A.; PAULA, A.L.; TREVISAN, A.P.; ANTES, R.B. Qualidade de processamento de tubérculos de batata produzidos sob diferentes disponibilidades de nitrogênio. Ciência Rural, Santa Maria, v.36, n.2, p.660-663, mar./abr. 2006.

PASTORINI, L.H.; BACARIN, M.A.; TREVIZOL, F.C.; BERVALD, C.M.P.; FERNANDES, H.S. Produção e teor de carboidratos não estruturais em tubérculos de batata obtidos em duas épocas de plantio.

Horticultura Brasileira, Brasília, v.21, n.4, p.660-665, out./dez. 2003.

PEREIRA, A. da S.; SILVA, R. da S.; BENDER, C.I.; FERRI, M.L.; VENDRUSCOLO, J.L. Genótipos de batata com baixo teor de açúcares redutores. Horticultura Brasileira, Brasília, v.25, n.2, p.220-223, abr./jun. 2007.

RICHARDSON, D.L.; DAVIES, H.V.; ROSS, H.A.; MACKAY, G.R. Invertase activity and its relations to hexose accumulation in potato tubers. Journal of Experimental Botany, v.41, p.95-99, 1990.

ROBLES, W.G.R. Dióxido de carbono via fertirrigação em batata (Solanum tuberosum L.) sob condição de campo. 2003. 160p. Tese (Doutorado em Agronomia)Escola Superior de Agricultura Luiz de Queiroz, Piracicaba, 2003. 
SANTERRE, C.R.; CASH, J.N.; CHASE, R.W. Influence of cultivar, harvest-date and soil nitrogen on sucrose, specific gravity and storage stability of potatoes grown in Michigan. American Potato Journal, v.63, p.99-110, 1986.

SHAN, L.; SATTELMACHER, B.; KUTZMUTZ, E.; MÜHLING, K.H.; DITTERT, K. Influence of nitrogen nutrition on tuber quality of potato with special reference to the pathway of nitrate transport into tubers. Journal of Plant Nutrition, v.27, n.2, p.341350, 2004.
SOWOKINOS, J.R. Biochemical and molecular control of cold-induced sweetening in potatoes. Amercian Journal Potato Research, v.78, p.221-236, 2001.

WESTERMANN, D.T.; TINDALL, T.A.; JAMES, D.W.; HURST, R.L. Nitrogen and potassium fertilization of potatoes: sugars and starch. American Potato Journal, v.71, p.433-454, 1994.

ZRENNER, R.; SCHÜLER, K.; SONNEWALD, U. Soluble acid invertase determines the hexoseto-sucrose ratio in coldstored potato tubers. Planta, Berlin, v.198, p.246-252, 1996. 